\title{
LECTURAS SOBRE IMPLEMENTACIÓN
}

Jorge Iván Cuervo R.

El Centro de Investigación y Docencia Económica (CIDE) de México publicó tres importantes libros entre 2018 y 2019 sobre el tema de la implementación de políticas públicas: Implementación de politicas públicas. Una antología, bajo la coordinación editorial de María del Carmen Pardo, Mauricio I. Dussauge Laguna y Guillermo M. Cejudo, reconocidos profesores e investigadores de ese importante centro de Pensamiento, Docencia e Investigación de México; Variaciones de implementación. Ocho casos de politica pública y Las burocracias a nivel de calle.

Implementación de politicas y Las burocracias a nivel de calle son una antología de textos clásico traducidos del inglés al español por Mónica de la Colina González y Suzanne D. Stephens, que contiene textos clásicos de Brian W. Hogwood, Peter L. Hupe, Peter J. May, Paul Cairney, Michael Hill, Michael Lipsky, Steven Maynard-Moody, Shannon Portillo, Heather C. Hill, Soren C. Winter, Anat Gofen, entre otros autores, sobre un tema que en América Latina ha tenido poco desarrollo teórico y de investigación, ya que ha sido dejado a la reflexión sobre la gestión pública sacándola del análisis de política pública, que es su espacio original.
La reflexión sobre implementación de políticas en español es escasa, y estas antologías constituyen un gran aporte para conocer los razonamientos que se vienen dando en el campo de la disciplina desde los años ochenta del siglo pasado. En realidad, el análisis en profundidad de las diferentes fases del proceso de formación de la política pública es escaso en Hispanoamérica, donde se privilegia el estudio en abstracto y la reproducción acrítica de modelos desarrollados en otras latitudes. Igualmente, es escaso el análisis aplicado en cada una de las fases de la política pública, y de ahí la importancia del libro Variaciones de implementación, donde se revisan ocho casos de estudio en México, como parte de un proyecto del cIDE con apoyo de la William and Flora Hewlett Foundation desde el año de 2015, y que constituye un valioso ejemplo de cómo aplicar el análisis de política pública -en fase de implementación- a realidades de la acción gubernamental.

Implementación de políticas públicas. Una antología recoge diez importantes ensayos publicados en Estados Unidos y Europa en la última década, que retoman la vieja discusión -planteada por Wildasky- sobre la brecha

\footnotetext{
* Candidato a Doctor en Derecho, Universidad Externado de Colombia. Magíster en Gestión y Políticas Públicas. Docente-investigador de la Facultad de Finanzas, Gobierno y Relaciones Internacionales, Universidad Externado de Colombia, Bogotá (Colombia). [jorge.cuervo@uexternado.edu.co], [https://orcid.org/0000-0003-2742-0446] Para citar esta reseña:

Cuervo R., J. I.( 2020). Reseńa Lecturas sobre Implementación. Opera, 27, 227-230 DOI: https://doi.org/10.18601/16578651.n27.11
} 
existente entre los diseńadores de la política pública y los gestores públicos encargados de realizar la implementación, lo cual se agudiza en los llamados gobiernos subnacionales donde, generalmente, la capacidad institucional es menor que en el sector central de gobierno. Por ejemplo, en el caso colombiano, el estudio sobre la formulación y la implementación de políticas públicas en gobiernos locales es bastante escaso y se limita a algunos programas en Bogotá y Medellín, trabajos realizados por algunas universidades como Andes y Eafit, respectivamente.

La lectura del "Estudio introductorio" y de los diez ensayos nos permite ver cómo en América Latina -y Colombia no es la excepción-, el estudio de las políticas públicas se hace disociado de los estudios sobre administración y gestión pública, y sabemos muy poco de las condiciones que se necesitan para la implementación de políticas, tanto en términos de capacidades institucionales como de conocimiento de los funcionarios, pero también que la fase de implementación no es ajena al diseño y que un horizonte de continuidad y estabilidad de la política, que identifique actores y mecanismos de coordinación -institucionales, presupuestales, jurídicos-, puede y debe ser previsto desde el mismo diseño. May llama la atención sobre el error común de responsabilizar de los malos resultados de la política a su diseño y no a su implementación.

Igualmente, algunos de los ensayos recogidos en el libro (Carney y Satren) destacan la importancia de incorporar actores no estatales en los procesos de implementación, es decir, privilegiar los modelos bottom-up que, de alguna manera, incorporan nuevos modelos de gobernanza bajo la premisa de que un error de implementación es creer que simplemente se trata de ejecutar y de cumplir al pie de la letra el manual del diseño, desconociendo la complejidad de toda política pública. Como señalan Hogwood y Gunn en su texto, la implementación perfecta de una política es prácticamente imposible dada la complejidad del proceso de formación de la política misma, y la imposibilidad de prever todas las vicisitudes de la implementación que suelen presentarse con crisis políticas, cambios de gobierno, recortes presupuestales, cambios de funcionarios, además de la presencia activa o reactiva de diferentes actores, lo cual le permite a un autor como Hupe hablar de la tesis de la implementación incongruente, esto es, la imposibilidad de una implementación perfecta.

Estas reflexiones teóricas y resultados de investigaciones se complementan con los ocho estudios de caso que se presentan en Variaciones de implementación, proyecto de investigación que parte por reconocer que "El énfasis puesto en el diseño o en la evaluación de las políticas públicas no tiene un equivalente en el análisis de la implementación", problema muy común en América Latina donde, como se lee en el estudio introductorio, se ha transitado de la planificación como la herramienta central de la gestión gubernamental al monitoreo y la evaluación, sin detenerse en la construcción de capacidades para la implementación de políticas públicas, citando a Cortázar Velarde (2007). El libro es una invitación a iniciar una agenda de investigación, no solo en la fase de implementación, sino también en todas las fases de formación de la política pública, una agenda de investigación que trascienda la revi- 
sión teórica foránea y nos permita avanzar en modelos propios de análisis relacionados con nuestra particularidad institucional.

Finalmente, el libro Las burocracias a nivel de calle (Street-level Bureaucracy) constituye una verdadera novedad para el público hispano-parlante de un tema sobre el que se ha trabajado poco en estas latitudes. Así como se ha dejado el análisis de las burocracias a la administración pública, desligada del proceso de formación de la política pública, muy poco se ha reflexionado sobre el burócrata -término genérico- que se encuentra en la base de la implementación, generalmente trabajando con las poblaciones objetivo y beneficiarias de los programas y proyectos que contienen las políticas públicas. El abandono de este campo de estudio en América Latina va de la mano de la transformación del aparato estatal y de la evidencia de que buena parte del recurso humano que trabaja en el Estado ya no lo hace bajo vinculación laboral con vocación de permanencia, sino por contratos de corto tiempo y de manera interrumpida, lo que afecta la continuidad en los procesos de dichas políticas.

Fue Michael Lipsky -de quien el libro trae un trabajo pionero- quien introdujo el tema para sumar a la complejidad de la implementación de políticas, aquellos relacionados con las circunstancias laborales, los climas organizacionales de los organismos públicos y las actitudes de dichos burócratas que pueden resignificar los objetivos de los programas y proyectos con sus intereses y valores, un tema que ya habían planteado Pressman y Wildasky; si bien el énfasis de estos autores fue puesto en las estructuras administrativas y en los procedimientos burocráticos, Lipsky se concentra en evidenciar el grado de discrecionalidad de los burócratas de nivel de calle como una variable de análisis en la fase de la implementación. En el caso colombiano es sabido que muchas de estas personas que caben en esta categoría son contratistas del Estado, con un régimen laboral precario y una alta rotación, lo cual incide en la continuidad de las políticas y en la trazabilidad de los procesos de un gobierno a otro, factor que puede ayudar a explicar uno de los puntos más críticos de una política pública, como lo es su permanencia en el tiempo. Dentro del universo del burócrata del nivel de calle, según la literatura que nos presenta el libro en los diez ensayos traducidos, estarían los profesores de los colegios, el personal de salud de los hospitales, los policías, los jueces, los inspectores sanitarios, los gestores sociales $y$, en general, las personas que en los diferentes programas y proyectos no participaron en el diseño, pero son claves para lograr los objetivos de las políticas públicas.

En el proceso de formación de una política participan distintos niveles: el directivo, encargado de definir los objetivos y los lineamientos generales que, en el caso colombiano, corresponde en el nivel nacional al presidente de la República con sus ministros y directores de departamentos administrativos, y en el nivel territorial a gobernadores y alcaldes con sus secretarios de despacho, todos ellos en el marco de los planes de desarrollo; los llamados mandos medios encargados de materializar esas políticas y lineamientos generales en programas y proyectos, en muchos casos acompañados de los analistas de política, y los burócratas de nivel de calle, quienes generalmente no participan de la fase del diseño pero 
son las personas encargadas de materializar los contenidos en la prestación de los servicios estatales, son la "cara visible del Estado" ante el ciudadano. Un ejemplo de su influencia en el sector educativo radica en que para mejorar la calidad de la educación en la enseñanza media necesariamente tendrá que contar con el maestro que en el salón de clase materialice este propósito. El margen de discrecionalidad de interpretación de estas personas respecto de los objetivos y contenidos de las políticas constituye el núcleo de esta literatura (NBC) novedosa para el ámbito latinoamericano. La evidencia indica, entonces, que "los comportamientos y las acciones del personal público a nivel de calle tienen implicaciones fundamentales para la implementación, pero también para el diseño de las políticas", por cuanto el margen de discrecionalidad puede incidir en el alcance de los logros de las políticas y, muchas veces, redireccionarlas, y, como lo señala el "Estudio introductorio", "convertirse, de facto, en los reformuladores de la política pública".

El libro empieza con el prólogo de Michael Lipsky a la nueva edición de su texto clásico Street-Level Bureaucracy, Dilemas of Individual in Public Services, de 2010, seguido de un texto de Steven Maynard-Moody y Shanon Portillo que nos acerca al estado del arte en el tema de la burocracia de nivel de calle, que resalta los cinco temas claves que son objeto de discusión en esta literatura: el estatus de este tipo de burocracia y su contacto directo con los ciudadanos, el procesamiento de casos y de procedimientos en el día a día, la discrecionalidad que caracteriza a esta población en el ejercicio de sus actividades, la autonomía de la decisión como atributo inherente a esta actividad y el rol que tienen en el proceso de la política pública, tanto en fase de implementación como de rediseñadores de facto de la misma. Los ocho capítulos restantes profundizan en diversos aspectos de este campo de análisis y constituyen un invaluable complemento a la literatura sobre implementación de los otros dos libros objeto de esta reseña.

Los tres textos reseńados constituyen una invitación del CIDE a los analistas de política pública en América Latina para abrir y desarrollar una agenda de investigación en la fase de implementación de políticas públicas, pero debe servir también como invitación para estructurar y desarrollar una agenda robusta de investigación de los procesos de formación de las políticas públicas en cada uno de los países, con casos aplicados y con reflexiones que recojan los aportes del desarrollo de la disciplina del Análisis de Política Pública en Estados Unidos, Canadá y Europa, y, por qué no, en otros países y continentes (los desarrollos en países como Australia, Israel, Japón aún nos son desconocidos), pero contrastados con las realidades institucionales, políticas y culturales de América Latina, de manera que se pueda tener un discurso propio que explique y permita transformar nuestras realidades sociales. Estos tres libros -que se suman a algunos otros que ha publicado el CIDE, como la Antología sobre evaluación de 2015-constituyen un punto de partida para la siguiente fase del análisis de política pública en la región, que es la de pasar de la adopción a la adaptación, a una fase con una agenda de investigación y de transformación propias. 